\title{
Ecological niche complexity of invasive and native cryptic species of the Bemisia tabaci species complex in China
}

\section{Yantao Xue ( $\nabla$ xueyantao@ioz.ac.cn )}

Institute of Zoology Chinese Academy of Sciences https://orcid.org/0000-0001-6894-6183

\section{Congtian Lin}

Institute of Zoology Chinese Academy of Sciences

\section{Yaozhuo Wang}

Hebei University College of Life Sciences

\section{Yibo Zhang}

Chinese Academy of Agricultural Sciences Institute of Plant Protection

\section{Liqiang Ji}

Institute of Zoology Chinese Academy of Sciences

\section{Research Article}

Keywords: Bemisia tabaci, Cryptic species, Invasive species, MaxEnt, Niche differentiation, Potential distribution

Posted Date: March 22nd, 2021

DOI: https://doi.org/10.21203/rs.3.rs-342457/v1

License: (a) (i) This work is licensed under a Creative Commons Attribution 4.0 International License. Read Full License 


\section{Abstract}

Bemisia tabaci is an important pest of agricultural and horticultural crops worldwide and comprises a complex of cryptic species. In China, the introduction of the two invasive cryptic species, Middle East-Asia Minor 1 (MEAM1) and Mediterranean (MED), has considerably affected the ecological niche of the native cryptic species. Based on occurrence records obtained through field surveys and high-resolution environmental data, ecological niche models were established to predict the distribution of invasive and native cryptic species of $B$. tabaci in China using the MaxEnt model. The models showed that the suitable range, the important environmental variables affecting the distribution of the cryptic species, and the adaptation range of the main environmental variables related to them were different. The findings of this study showed that the $B$. tabaci species complex possesses a complex ecological niche. The distribution range and niche breadth of the invasive cryptic species exceeds that of the native cryptic species in the order of MED > MEAM1 > China1 > Asia1. There are different degrees of niche overlap and range overlap among the different cryptic species. This study, therefore, revealed the differences in the distribution and ecological niche of the invasive and native cryptic species of $B$. tabaci in China. The findings of this study contribute to the ecological knowledge of $B$. tabaci, which will be useful in the development of prevention and control strategies for this pest in China.

\section{Key Messages}

1. Bemisia tabaci is a species complex composed of many cryptic species, including two invasive cryptic species, MED and MEAM1

2. The ecological niche of invasive and native cryptic species in China was evaluated using an ecological niche modelling approach based on field survey

3. The ecological niche of the $B$. tabaci species complex was characterised as being complex, which may explain differences in the distribution, dispersal, and damage of cryptic species.

\section{Introduction}

Bemisia tabaci (Gennadius) (Hemiptera: Aleyrodidae) is one of the most threatening pests in many crops worldwide (De Barro et al. 2011). This species directly affects more than 600 plant species by feeding on them, excreting honeydew, and transmitting plant viruses, resulting in significant agricultural losses (Simmons et al. 2008; Jones 2003; Navas-Castillo et al. 2011; Oliveira et al. 2001). Recent genomic studies have shown that $B$. tabaci is a unique species complex composed of more than 42 morphologically indistinguishable cryptic species (Kanakala and Ghanim 2019; De Barro et al. 2011). Among the cryptic species, the Middle East-Asia Minor 1 (MEAM1, formerly referred to as biotype B) and Mediterranean (MED, formerly referred to as biotype Q) are the most widely distributed and destructive invasive species (Perring 2001; Tay et al. 2012).

B. tabaci was identified in China in the 1940 s, but was not considered a serious pest until the arrival of the two invasive cryptic species. MEAM1, which was the first invasive cryptic species, was first identified in 
China in the mid to late 1990s and has expanded rapidly since then, replacing native cryptic species and Trialeurodes vaporariorum (Hemiptera: Aleyrodidae) in several regions in China (Luo et al. 2002; Li et al. 2016). MED, another invasive cryptic species, was first identified in 2003, and has displaced MEAM1 as the most distributed species in several regions in China (Chu et al. 2006; Pan et al. 2011; Chu et al. 2010; Wang et al. 2010). This is because MED is pesticide resistant and has a higher competition for field crops (Sun et al. 2013; Horowitz et al. 2020). Recent surveys in China have shown that MED is the dominant cryptic species of $B$. tabaci in most regions and coexists with MEAM1 in some regions, while some of the 18 native cryptic species identified in China are even the dominant species in some restricted regions (Hu et al. 2018; Li et al. 2016; Hu et al. 2014; Zheng et al. 2016; Hu et al. 2015; Hu et al. 2011; Liu et al. 2012; Jiu et al. 2017a).

In-depth knowledge of an insect's ecological niche is essential for the formulation of effective pest management strategies. However, $B$. tabaci is difficult to manage in agricultural landscapes because of its small body size, wide host range, and wide ecological niche (Perring 2001). Moreover, different cryptic species of $B$. tabaci pose different risks to agriculture due to their biological traits, insecticide resistance, host range, endosymbionts, and ability to transmit viruses (Luan et al. 2013; Liu et al. 2007; Zang et al. 2006; Xu et al. 2011; Shi et al. 2018; Horowitz et al. 2020; Tang et al. 2018; Guo et al. 2019). Previous studies on the distribution and population dynamics of $B$. tabaci in China have relied mainly on field surveys (Chu et al. 2007; Jiu et al. 2017b; Hu et al. 2014). However, detailed information of the ecological niche complexity of $B$. tabacispecies complex in China is still lacking, and the roles of ecological and anthropogenic factors in the distribution of the cryptic species remain unknown.

Ecological niche modelling (ENM) is a widely accepted approach in studying the potential distribution patterns of species using specific algorithms (Peterson and Soberon 2012). Among ENMs, maximum entropy modelling (MaxEnt), which aims to approximate the realised niche of species by characterising species-environment relationships using species occurrence data and environmental covariates, has the advantages of easy operation, short model running time, small sample size requirements, and superior performance (Phillips et al. 2006; Phillips and Dudik 2008; Hernandez et al. 2006; Pearson et al. 2007). It has been used to predict the potential distribution of species, especially invasive organisms, as well as the interactions between species distribution and environments (Orsted and Orsted 2019; Kumar et al. 2014). Earlier studies have used the MaxEnt model to make effective predictions of the distribution of $B$. tabaci in North India (Prabhulinga et al. 2017), sub-Saharan Africa (Mudereri et al. 2020), South America (ParedesMontero et al. 2020), and globally (Ramos et al. 2018). Zhao et al. (2019) used the MaxEnt model combined with GIS technology to predict suitable areas of $B$. tabaci in China. However, the major drawback of the above studies was that $B$. tabaci was considered a species rather than a species complex, and only specific cryptic species were examined. For a detailed study of the $B$. tabaci species complex, it is necessary to consider the different cryptic species.

The ability of an insect pest to survive in an area relies on several factors. Based on the biological characteristics of $B$. tabaci, the key environmental factors that determine its geographical distribution are temperature and precipitation (Naranjo et al. 2010). Moreover, these variables are correlated with 
elevation, which may thus influence the occurrence and reproduction of $B$. tabaci by affecting temperature, precipitation, vegetation, and solar radiation (Azrag et al. 2018; Mudereri et al. 2020). Additionally, since the survival of $B$. tabaci depends on the host plants, which includes several agricultural cash crops, this pest is sensitive to land-use/land-cover types. Therefore, it is necessary to consider the effects of bioclimatic variables, elevation, and land-use/land-cover variables on distribution and ecological niches of $B$. tabaci.

In the present study, based on field surveys and systematic collection of $B$. tabaci species complex across China and records in the literature, the habitat suitability and distribution of the invasive and native cryptic species of $B$. tabaci was estimated using MaxEnt software. This study aimed to identify the different ecological niches of $B$. tabaci cryptic species and the relationship between their presence and key environmental variables.

\section{Materials And Methods}

\subsection{Sample Collection and Occurrence Data}

A large-scale sampling of $B$. tabaci was conducted in open-fields across China during the peak cropgrowing season from 2016 to 2018 . We collected $B$. tabaci individuals from 358 geographical locations in 142 districts in 31 provinces in China. Adults from at least 20 individuals were collected from different leaves of separate plants at each site, and at least three sites were surveyed per field. Every individual was identified as a cryptic species using molecular biological methods (Dinsdale et al. 2010; De Barro et al. 2011). We examined published data in the literature on the distribution of $B$. tabaci in China for sampling information in the wild, including coordinates and cryptic species types, to complement our sampling effort (Hu et al. 2018).

Although extensive investigations and collections have been made, some cryptic species have fewer occurrence records in China. Therefore, four cryptic species with relatively large open-field occurrence records, two invasive cryptic species (MED and MEAM1) and two native cryptic species (China1 and Asia1), were selected for further analysis. The occurrence data are often clustered in geographic space, and models created using such data may produce erroneous results due to spatial autocorrelation (Boria et al. 2014). To reduce or minimise sampling deviation and spatial autocorrelation, the Spatially Rarefy Occurrence Data Tool in the SDM toolbox v2.4 (http://sdmtoolbox.org/) (Brown 2014) was used to rarefy occurrence records in ArcGIS 10.6 (ESRI). After filtering, 234, 59, 38, and 48 presence records of MED, MEAM1, Asia1, and China1, respectively, remained as the occurrence data for habitat suitability modelling (Fig. 1, Table S1).

\subsection{Environmental Variables}

Three types of environmental variables, with strong correlation with the occurrence and reproduction of $B$. tabaci, were introduced in this study, including 19 bioclimatic variables (bio1-bio19), elevation (elev), and land-use/land-cover variables (LULC) (Table 1). The 19 bioclimatic variables and elevation were obtained 
from the WorldClim Global Climate Database (version 2.1, http://www.worldclim.org) with a spatial resolution of 30 arc-seconds (approximately $1 \mathrm{~km}$ at the equator) (Fick and Hijmans 2017). The data of land-use/land-cover variables were obtained from the Resource and Environment Science and Data Center (http://www.resdc.cn), which developed multiple levels for the classification of land-use/land-cover types. The most general or aggregated classification (level I) included broad land-use/land-cover categories, and within each level I class were a number of detailed land-use/land-cover classes (level II) (Table 2).

When simulating the potential distribution of species, multicollinearity among environmental variables can hinder the analysis of species-environment relationships (Thuiller et al. 2008). To eliminate this problem and improve model performance, the multivariate tool in the spatial analyst tools from the ArcToolbox of ArcGIS was used to assess the correlations between environmental variables. If two variables correlated $(r \geq|0.85|)$, only one variable was included based on realistic biological relevance to B. tabaci (Table S2). Finally, nine environmental variables, namely annual mean temperature (bio1), mean diurnal range (bio2), isothermality (bio3), annual temperature range (bio7), annual precipitation (bio12), precipitation seasonality (bio15), precipitation of the coldest quarter (bio19), elevation (elev), and LULC were selected for further study (Table 1).

\subsection{Model Development and Evaluation}

MaxEnt software 3.4.4 (http://biodiversityinformatics.amnh.org/open_source/maxent/) (Phillips et al. 2006) was used to predict the suitable areas and examine the impacts of environmental variables on the distribution of the four cryptic species of $B$. tabaci in China. The model was set to use $75 \%$ of the occurrence points as the training data and the remaining $25 \%$ as the test data. The "create response curve" option was selected to show how the relative probability of occurrence depended on the value of each environmental variable. The jackknife technique was used to estimate the contribution of a single environment variable. Ten replicated runs of the subsample method were completed to build the model. The maximum number of iterations was increased from 500 (default) to 5,000 to optimise convergence. The "fade-by-clamping" option was selected to eliminate extrapolations outside the environmental range (Owens et al. 2013). The cloglog output format was checked for model analysis.

The R package "ENMeval" was used to optimise the models to avoid overfitting by adjusting the feature classes (FCs) and regularisation multiplier (RM) (Muscarella et al. 2014). MaxEnt provides five feature types: linear $(L)$, quadratic $(Q)$, hinge $(H)$, product $(P)$, and threshold $(T)$. Nine different FCs $(L, L Q, L H, L Q H$, LQP, QHP, LQHP, QHPT, and LQPHT) were tested with RM ranging from 0.5 to 4.0 in increments of 0.5 . The "Checkerboard2" approach was applied by calculating the lowest delta value of the Akaike information criterion coefficient (AICc) to select the final MaxEnt models for each cryptic species. Finally, the FCs of LQP, L, LQP, and LQHP, with RM of 1.5, 0.5, 4.0, and 2.0, were selected to execute the final model for MED, MEAM1, Asia1, and China1, respectively (Fig. 2).

The MaxEnt models were evaluated using a threshold independent receiver operating characteristic (ROC) curve, and the area under the curve (AUC) was positively correlated with the performance of the prediction 
model (Peterson et al. 2008). Thus, the model performance was classified depending on the AUC value as failing (0.5-0.6), poor (0.6-0.7), fair (0.7-0.8), good (0.8-0.9), or excellent (0.9-1.0) (Phillips et al. 2006).

\subsection{Habitat and ecological niche analysis}

The Maximum Test Sensitivity Plus Specificity (MTSPS) threshold was chosen to determine the suitable and unsuitable habitats of $B$. tabaci, as the thresholds maximising sensitivity and specificity performed well on presence datasets (Liu et al. 2016). Based on this, four suitability levels of distribution regions were defined for each cryptic species: 1 ) unsuitable (P < MTSPS), 2) low suitable (MTSPS $\leq P<0.5), 3$ ) moderately suitable $(0.5 \leq P<0.7)$, and 4$)$ highly suitable $(P \geq 0.7)$.

To compare the differences in ecological niches among B. tabaci cryptic species, the MaxEnt outputs were imported into ArcGIS for suitability classification and visual interpretation, and the suitable habitat areas of the cryptic species were further counted using zonal statistics. Subsequently, the dominant environmental variables affecting the distribution of the four cryptic species were analysed based on relevant measures (i.e. jackknife results, percentage contribution, and permutation importance), and the relationships between the probability of their presence and variables were described from the response curves. The adaptation ranges of the nine environmental variables for the four cryptic species were extracted and then calculated separately using extract by points in ArcGIS. Furthermore, niche breadth, niche overlap, and range overlap tests were performed using ENMTools 1.3 (Warren et al. 2010) based on MaxEnt outputs. In the niche overlap test, Schoener's Dindex (Schoener 1968) and Hellinger's-based I index (Warren et al. 2008) were used to measure the similarities between each pair of cryptic species habitat suitability models. These values were between 0 and 1 , with higher values corresponding to higher indicators (Warren et al. 2010).

\section{Results}

\subsection{Model Performance}

The MaxEnt models had high accuracy with average AUC values higher than 0.9, MED (0.922), MEAM1 (0.924), Asia1 (0.971), and China1 (0.953) (Fig. 3). The habitat distributions of the four cryptic species generated using MaxEnt modelling were reliable and could be used for further analysis.

\subsection{Important Environmental Variables}

Based on the results of the modelling, the important environmental variables affecting the distribution of the cryptic species were different. However, the important environment variables affecting the distribution of MED and MEAM1 were similar. LULC, elevation, and bio1 were the top three most important factors among the nine environmental variables, with a cumulative contribution of $70.7 \%$ for MED and $89.4 \%$ for MEAM1 (Fig. 4a-4b, Table 3). The permutation analysis ranked those variables as the top three most important variables, although in different order for MED and MEAM1 (Table 3). Furthermore, the result of the jackknife test showed that LULC have the most useful information by themselves and can contribute 
more information that is not present in the other variables (Fig. 4a-4b). However, the results for the two native cryptic species were different from those obtained for the invasive species. Bio1 and bio3 were the main factors affecting the distribution of Asia1, with a cumulative contribution of $94.0 \%$ (Table 3 ). Additionally, bio1 had the highest permutation importance for Asia1 (Table 3) and recorded the most useful information compared with the other variables (Fig. 4c). For China1, the main factors were bio19, elevation, bio12, and LULC, with a cumulative contribution of $83.8 \%$ (Fig. 4d, Table 3). Among the variables, bio1 and elevation had a higher permutation importance (Table 4). The result of the jackknife test showed that bio1 had the most useful information by itself, and bio7 had the most information that was not present in the other variables (Fig. 4d). Overall, temperature-related variables contributed more than precipitation-related variables to the models of the four cryptic species.

\subsection{Environmental Variables Response}

The different trends of the response curve of the same variable in the models indicated the appropriate environmental requirements of the different cryptic species. The probability of the presence of the cryptic species increased with an increase in bio1, except for the probability of the presence of MED, which exhibited a quadratic pattern (Fig. 5a). The probability of the presence of MED and China1 showed a quadratic pattern with an increase in bio2, peaking at approximately $8{ }^{\circ} \mathrm{C}$ and declining at higher temperatures, while that of MEAM1 and Asia1 both decreased with an increase in temperature (Fig. $5 \mathrm{~b}$ ). The probability of the presence of MED, MEAM1, and China1 decreased with an increase in bio3, while that of Asia1 increased with an increase in isothermality (Fig. 5c). The probability of the presence of MED and China 1 showed a quadratic pattern with an increase in bio7, peaking at approximately $20{ }^{\circ} \mathrm{C}$ and 30 ${ }^{\circ} \mathrm{C}$, respectively, and declining at higher temperatures, while that of MEAM1 and Asia1 both decreased with an increase in annual temperature range (Fig. 5d). The probability of the presence of MED and China1 showed a quadratic pattern with an increase in bio12, while the probability of the presence of MEAM1 and Asia 1 increased with an increase in annual temperature range (Fig. 5e). The probability of the presence of MED showed a quadratic pattern with an increase in bio15, the lowest value was recorded at approximately $80 \%$ and increased at higher percentages; however, the probability of the presence of the other three cryptic species decreased with an increase in precipitation seasonality (Fig. 5f). The probability of the presence of the four cryptic species increased with an increase in the precipitation of bio19 (Fig. $5 \mathrm{~g}$ ), while it decreased with an increase in elevation (Fig. 5h). Furthermore, the probabilities of the presence of the cryptic species in response to LULC were similar and different in some instances, with agriculture (Level I number 1), forest land (Level I number 2), and urban or built-up (Level I number 5) being the most important land types (Fig. 5i).

\subsection{Adaptation for Environmental Variables}

The adaptation ranges of the main environmental variables for the four cryptic species further illustrated the niche complexity of the $B$. tabaci species complex. There were significant differences in the adaptation range of the nine environmental variables (Fig. 6). The difference in the range of adaptation of the four cryptic species to bio1 indicated that invasive cryptic species were better adapted to lower temperatures than native cryptic species (Fig. 6a). The difference in bio3 and bio7 indicated that Asia1 had the lowest 
adaption to temperature variations (Fig. 6c-6d). For precipitation-related variables, the difference in adaptation range for bio12 and bio15 revealed that MED had a higher adaptation to areas with low precipitation and large seasonal variations in precipitation than the other cryptic species (Fig. 6e-6f). The result for elevation indicated that Asia1 had a wider adaptation range to elevation than the other three cryptic species (Fig. 6h). MED had the highest adaptation to a wide range of LULC, which were mainly agriculture (Level $₫$ number 1 ) and urban or built-up (Level $₫$ number 5 ). However, the other cryptic species had similar land preferences, which were mainly urban or built-up (Level $\triangle$ number 5 ) for MEAM1, and agriculture (Level $₫$ number 1) for Asia1 and China1 (Fig. 6i).

\subsection{Suitable Habitat Distribution}

The models showed areas of low to high habitat suitability for the four cryptic species of $B$. tabaci in China (Fig. 7). Generally, the distribution area of the invasive cryptic species was larger than that of native cryptic species. Among the four cryptic species, the two invasive cryptic species had similar habitat distribution. Specifically, MED and MEAM1 were distributed almost nationwide in China, except for parts of northwest, southwest, and northeast China, with the moderately and highly suitable habitats mainly located in northern, central, and eastern China for MED, and in northern, central, eastern, and southern China for MEAM1 (Fig. 7a-7b). Asia1 was mainly distributed in southwest and southern China (Fig. 7c), whereas China1 was mainly distributed in eastern, central, and southern China (Fig. 7d). In terms of the areas of suitable habitat, MED was the highest among the four cryptic species, followed by MEAM1, China1, and Asia1 in descending order (Table 4).

\subsection{Ecological Niche}

Ecological niche analysis showed that MED had the highest niche breadth followed by the remaining three in the order of MEAM1 > China1 > Asia1 (Table 5). We observed some degree of niche overlap between the four cryptic species. Both the $D$ and /indices indicated a high degree of niche overlap between MED and MEAM1 $(D>0.7,1>0.9$ ), indicating that their ecological niches might be similar, but not identical, followed by MEAM1 and China1 $(D>0.5, l>0.8)$. However, the other pairs of cryptic species did not share similar niches (Table 5). Range coverage analysis showed that MED and MEAM1 had the highest range coverage, followed by MED and Asia1, MEAM1 and Asia1, MEAM1 and China1, MED and China1, and Asia1 and China1, in descending order (Table 5). There was a large niche overlap between Asia1 and China1, while the range overlap was small (Table 5).

\section{Discussion}

In the present study, the occurrence data of $B$. tabaci species complex in China were collected during field surveys, with further identification of cryptic species using reliable molecular means. Moreover, apart from bioclimatic variables, elevation and land-use/land-cover variables were added to the MaxEnt model to improve the accuracy of the prediction of suitable areas for the cryptic species. The models used in the present study had a high degree of reliability. 
Among the cryptic species, MED and MEAM1 are the most invasive and destructive, affecting agricultural production globally (De Barro et al. 2011). During field surveys, we found that the two invasive cryptic species have been distributed in most parts of China, and that the distribution of the MED has gradually exceeded that of MEAM1 in recent years (Jiu et al. 2017b; Hu et al. 2018; Tang et al. 2020). However, native cryptic species were still dominant in some areas (Hu et al. 2015; Tang et al. 2018). It has been hypothesised that there are differences in the distribution patterns and ecological niches of invasive and native cryptic species of $B$. tabaci. The modelling results of the present study proved this hypothesis. The four cryptic species that were examined in the present study, two invasive cryptic species (MED and MEAM1) and two native cryptic species (China1 and Asia1), had specific habitat distribution patterns and ecological niches in China, which was consistent with the results of field surveys.

The four cryptic species had specific sets of dominant environmental variables and exhibited different adaptations to these variables. The type of land-use/land-cover is an important factor affecting the occurrence of MED and MEAM1 in China, with urban or built-up land having the highest suitability for the survival of the pest, followed by agricultural land. This indicated that the survival of the invasive cryptic species of $B$. tabaci depends on the host plant, which may be closely related to human activities. The results of the present study showed that $B$. tabaci occurred mainly at low elevations and its probability of survival decreased with an increase in elevation, which is consistent with a previous study in China (Zhao et al. 2019). However, some cryptic species may have a wider adaptability to changes in elevation. Among the bioclimatic variables, temperature-related variables had a greater effect on the distribution of $B$. tabaci than precipitation-related variables, with precipitation barely playing a role in the distribution of Asia1. Studies have shown that MED and MEAM1 can survive in the tropics where temperature is higher (Ramos et al. 2018; Xiao et al. 2016). The results of the present study indicated that low temperature is a limiting factor for the occurrence and survival of MED and MEAM1 in the wild in China. However, with the extensive presence of greenhouses, MED and MEAM1 may be able to survive in areas previously not suitable for them.

The habitat range and size and niche breadth of the invasive cryptic species exceeded that of the native cryptic species significantly, which may be a reason why the invasive species are more threatening to crop production than the native species. The niche overlap and range overlap between MED and MEAM1 was large, indicating that there may be a relatively intense competitive ecological niche relationship between them. However, the reasons for MED replacing the MEAM1 found in field surveys in some areas, in addition to environmental factors, need to be further investigated.

The findings of the present study explained the above phenomenon found in field surveys from the perspective of the ecological niche by indicating that the differences in the distribution of the different cryptic species may be due to differences in ecological niches. The results of the present study revealed that the B. tabaci species complex possesses complex ecological niches. Specifically, the ecological niche breadth of the invasive cryptic species was larger than that of the native cryptic species, suggesting that the invasive species were better adapted to different environments. Furthermore, the niche breadth of MED 
was larger than that of MEAM1, which may be a reason why MED has gradually replaced MEAM1 in some regions of China in recent years.

\section{Conclusion}

The B. tabaci species complex exhibited significant ecological niche complexity, including suitable area distribution, adaptability to environmental variables, ecological niche breadth, and niche overlap. This suggests the need for future studies to consider the cryptic species in isolation, especially in terms of ecology. Moreover, when performing pest management, prevention and field management should be strengthened to prevent the introduction of invasive cryptic species in suitable areas that are yet to be infested by the invasive cryptic species. This study also provides an approach for conducting related research in other regions of the world.

\section{Declarations}

\section{Funding}

The 13th Five-year Informatization Plan of Chinese Academy of Sciences (XXH13505-03-102)

\section{Conflict of interest}

The authors declare that they have no conflicts of interest.

\section{Availability of data and material}

All data generated or analysed during this study are included in this published article and the supplementary information files.

\section{Code availability}

Not applicable

\section{Acknowledgements}

We thank the institutions and individuals who provided assistance in the sampling process. This work was supported by the 13th Five-year Informatization Plan of Chinese Academy of Sciences (XXH1350503-102).

\section{References}

Azrag AGA, Pirk CWW, Yusuf AA, Pinard F, Niassy S, Mosomtai G, Babin R (2018) Prediction of insect pest distribution as influenced by elevation: Combining field observations and temperature-dependent 
development models for the coffee stink bug, Antestiopsis thunbergii (Gmelin). Plos One 13 (6):18. https://doi.org/10.1371/journal.pone.0199569

Boria RA, Olson LE, Goodman SM, Anderson RP (2014) Spatial filtering to reduce sampling bias can improve the performance of ecological niche models. Ecol Model 275:73-77.

https://doi.org/10.1016/j.ecolmodel.2013.12.012

Brown JL (2014) SDMtoolbox: a python-based GIS toolkit for landscape genetic, biogeographic and species distribution model analyses. Methods Ecol Evol 5 (7):694-700. https://doi.org/10.1111/2041$210 x .12200$

Chu D, Jiang T, Liu GX, Jiang DF, Tao YL, Fan ZX, Zhou HX, Bi YP (2007) Biotype status and distribution of Bemisia tabaci (Hemiptera : Aleyrodidae) in shandong province of China based on mitochondrial DNA markers. Environ Entomol 36 (5):1290-1295. https://doi.org/10.1603/0046225x(2007)36[1290:Bsadob]2.0.Co;2

Chu D, Wan FH, Zhang YJ, Brown JK (2010) Change in the biotype composition of Bemisia tabaci in Shandong Province of China from 2005 to 2008. Environ Entomol 39 (3):1028-1036. https://doi.org/10.1603/EN09161

Chu D, Zhang YJ, Brown JK, Cong B, Xu BY, Wu QJ, Zhu GR (2006) The introduction of the exotic Q biotype of Bemisia tabaci from the Mediterranean region into China on ornamental crops. Fla Entomol 89 (2):168174. https://doi.org/10.1653/0015-4040(2006)89[168:Tioteq]2.0.Co;2

De Barro PJ, Liu SS, Boykin LM, Dinsdale AB (2011) Bemisia tabaci: A Statement of Species Status. In: Berenbaum MR, Carde RT, Robinson GE (eds) Annual Review of Entomology, Vol 56, vol 56. Annual Review of Entomology. pp 1-19. https://doi.org/10.1146/annurev-ento-112408-085504

Dinsdale A, Cook L, Riginos C, Buckley YM, De Barro P (2010) Refined Global Analysis of Bemisia tabaci (Hemiptera: Sternorrhyncha: Aleyrodoidea: Aleyrodidae) Mitochondrial Cytochrome Oxidase 1 to Identify Species Level Genetic Boundaries. Ann Entomol Soc Am 103 (2):196-208.

https://doi.org/10.1603/an09061

Fick SE, Hijmans RJ (2017) WorldClim 2: new 1-km spatial resolution climate surfaces for global land areas. Int J Climatol 37 (12):4302-4315. https://doi.org/10.1002/joc.5086

Guo Q, Shu YN, Liu C, Chi Y, Liu YQ, Wang XW (2019) Transovarial transmission of tomato yellow leaf curl virus by seven species of the Bemisia tabaci complex indigenous to China: Not all whiteflies are the same. Virology 531:240-247. https://doi.org/10.1016/j.virol.2019.03.009

Hernandez PA, Graham CH, Master LL, Albert DL (2006) The effect of sample size and species characteristics on performance of different species distribution modeling methods. Ecography 29 (5):773785. https://doi.org/10.1111/j.0906-7590.2006.04700.x 
Horowitz AR, Ghanim M, Roditakis E, Nauen R, Ishaaya I (2020) Insecticide resistance and its management in Bemisia tabaci species. J Pest Sci 93 (3):893-910. https://doi.org/10.1007/s10340-02001210-0

Hu J, Chen YD, Jiang ZL, Nardi F, Yang TY, Jin J, Zhang ZK (2015) Global haplotype analysis of the whitefly Bemisia tabaci cryptic species Asia I in Asia. Mitochondrial DNA 26 (2):232-241. https://doi.org/10.3109/19401736.2013.830289

Hu J, De Barro P, Zhao H, Wang J, Nardi F, Liu SS (2011) An extensive field survey combined with a phylogenetic analysis reveals rapid and widespread invasion of two alien whiteflies in China. PLoS One 6 (1):e16061. https://doi.org/10.1371/journal.pone.0016061

Hu J, Jiang ZL, Nardi F, Liu YY, Luo XR, Li HX, Zhang ZK (2014) Members of Bemisia tabaci (Hemiptera: Aleyrodidae) cryptic species and the status of two invasive alien species in the Yunnan Province (China). J Insect Sci 14:1-8. https://doi.org/10.1093/jisesa/ieu143

Hu J, Zhang X, Jiang Z, Zhang F, Liu Y, Li Z, Zhang Z (2018) New putative cryptic species detection and genetic network analysis of Bemisia tabaci (Hempitera: Aleyrodidae) in China based on mitochondrial $\mathrm{COI}$ sequences. Mitochondrial DNA A DNA Mapp Seq Anal 29 (3):474-484.

https://doi.org/10.1080/24701394.2017.1307974

Jiu M, Hu J, Wang L-J, Dong J-F, Song Y-Q, Sun H-Z (2017a) Cryptic Species Identification and Composition of Bemisia tabaci (Hemiptera: Aleyrodidae) Complex in Henan Province, China. Journal of insect science (Online) 17 (3). https://doi.org/10.1093/jisesa/iex048

Jiu M, Hu J, Wang LJ, Dong JF, Song YQ, Sun HZ (2017b) Cryptic Species Identification and Composition of Bemisia tabaci (Hemiptera: Aleyrodidae) Complex in Henan Province, China. J Insect Sci 17 (3). https://doi.org/10.1093/jisesa/iex048

Jones DR (2003) Plant viruses transmitted by whiteflies. European Journal of Plant Pathology 109 (3):195-219. https://doi.org/10.1023/A:1022846630513

Kanakala S, Ghanim M (2019) Global genetic diversity and geographical distribution of Bemisia tabaci and its bacterial endosymbionts. PLoS One 14 (3):e0213946.

https://doi.org/10.1371/journal.pone.0213946

Kumar S, Neven LG, Yee WL (2014) Evaluating correlative and mechanistic niche models for assessing the risk of pest establishment. Ecosphere 5 (7):23. https://doi.org/10.1890/es14-00050.1

Li H, Pan H, Tao Y, Jiang D, Zhang Y, Chu D (2016) Species identification of indigenous Bemisia tabaci in agricultural areas in China. Acta Phytophylacica Sinica 43 (1):84-90

Liu CR, Newell G, White M (2016) On the selection of thresholds for predicting species occurrence with presence-only data. Ecol Evol 6 (1):337-348. https://doi.org/10.1002/ece3.1878 
Liu S-s, Colvin J, De Barro PJ (2012) Species Concepts as Applied to the Whitefly Bemisia tabaci Systematics: How Many Species Are There? J Integr Agric 11 (2):176-186. https://doi.org/10.1016/s20953119(12)60002-1

Liu SS, De Barro PJ, Xu J, Luan JB, Zang LS, Ruan YM, Wan FH (2007) Asymmetric mating interactions drive widespread invasion and displacement in a whitefly. Science 318 (5857):1769-1772. https://doi.org/10.1126/science.1149887

Luan JB, Yao DM, Zhang T, Walling LL, Yang M, Wang YJ, Liu SS (2013) Suppression of terpenoid synthesis in plants by a virus promotes its mutualism with vectors. Ecol Lett 16 (3):390-398. https://doi.org/10.1111/ele.12055

Luo C, Yao Y, Wang R, Yan F, Hu D, Zhang Z (2002) The use of mitochondrial cytochrome oxidase I (mt $\mathrm{COI})$ gene sequences for the identification of biotypes of Bemisia tabaci (Gennadius) in China. Acta Entomologica Sinica 45 (6):759-763

Mudereri BT, Kimathi E, Chitata T, Moshobane MC, Abdel-Rahman EM (2020) Landscape-scale biogeographic distribution analysis of the whitefly, Bemisia tabaci (Gennadius, 1889) in Kenya. International Journal of Tropical Insect Science. https://doi.org/10.1007/s42690-020-00360-z

Muscarella R, Galante PJ, Soley-Guardia M, Boria RA, Kass JM, Uriarte M, Anderson RP (2014) ENMeval: An R package for conducting spatially independent evaluations and estimating optimal model complexity for MAXENT ecological niche models. Methods Ecol Evol 5 (11):1198-1205. https://doi.org/10.1111/2041210x.12261

Naranjo SE, Castle SJ, de Barro PJ, Liu S-S (2010) Population dynamics, demography, dispersal and spread of Bemisia tabaci. In: Stansly PA, Naranjo SE (eds) Bemisia: bionomics and management of a global pest. Springer, Dordrecht, The Netherlands, pp 185-226

Navas-Castillo J, Fiallo-Olive E, Sanchez-Campos S (2011) Emerging virus diseases transmitted by whiteflies. Annu Rev Phytopathol 49:219-248. https://doi.org/10.1146/annurev-phyto-072910-095235

Oliveira MRV, Henneberry TJ, Anderson P (2001) History, current status, and collaborative research projects for Bemisia tabaci. Crop Protection 20 (9):709-723. https:// doi.org/ 10.1016/S0261-2194(01)00108-9

Orsted IV, Orsted M (2019) Species distribution models of the Spotted Wing Drosophila (Drosophila suzukii, Diptera: Drosophilidae) in its native and invasive range reveal an ecological niche shift. J Appl Ecol 56 (2):423-435. https://doi.org/10.1111/1365-2664.13285

Owens HL, Campbell LP, Dornak LL, Saupe EE, Barve N, Soberon J, Ingenloff K, Lira-Noriega A, Hensz CM, Myers CE, Peterson AT (2013) Constraints on interpretation of ecological niche models by limited environmental ranges on calibration areas. Ecol Model 263:10-18. https://doi.org/10.1016/j.ecolmodel.2013.04.011 
Pan H, Chu D, Ge D, Wang S, Wu Q, Xie W, Jiao X, Liu B, Yang X, Yang N, Su Q, Xu B, Zhang Y (2011) Further spread of and domination by Bemisia tabaci (Hemiptera: Aleyrodidae) biotype Q on field crops in China. J Econ Entomol 104 (3):978-985. https://doi.org/10.1603/ec11009

Paredes-Montero JR, Ibarra MA, Arias-Zambrano M, Peralta EL, Brown JK (2020) Phylo-biogeographical distribution of whitefly Bemisia tabaci (Insecta: Aleyrodidae) mitotypes in Ecuador. Ecosphere 11 (6):20. https://doi.org/10.1002/ecs2.3154

Pearson RG, Raxworthy CJ, Nakamura M, Peterson AT (2007) Predicting species distributions from small numbers of occurrence records: a test case using cryptic geckos in Madagascar. Journal of Biogeography 34 (1):102-117. https://doi.org/10.1111/j.1365-2699.2006.01594.x

Perring TM (2001) The Bemisia tabaci species complex. Crop Protection 20 (9):725-737. https://doi.org/10.1016/S0261-2194(01)00109-0

Peterson AT, Papes M, Soberon J (2008) Rethinking receiver operating characteristic analysis applications in ecological niche modeling. Ecol Model 213 (1):63-72. https://doi.org/10.1016/j.ecolmodel.2007.11.008

Peterson AT, Soberon J (2012) Species Distribution Modeling and Ecological Niche Modeling: Getting the Concepts Right. Nat Conserv 10 (2):102-107. https://doi.org/10.4322/natcon.2012.019

Phillips SJ, Anderson RP, Schapire RE (2006) Maximum entropy modeling of species geographic distributions. Ecol Model 190 (3-4):231-259. https://doi.org/10.1016/j.ecolmodel.2005.03.026

Phillips SJ, Dudik M (2008) Modeling of species distributions with Maxent: new extensions and a comprehensive evaluation. Ecography 31 (2):161-175. https://doi.org/10.1111/j.0906-7590.2008.5203.x

Prabhulinga T, Rameash K, Madhu TN, Vivek S, Suke R (2017) Maximum entropy modelling for predicting the potential distribution of cotton whitefly Bemisia tabaci (Gennadius) in North India. Journal of Entomology and Zoology Studies 5 (4 M):1002-1006

Ramos RS, Kumar L, Shabani F, Picanco MC (2018) Mapping global risk levels of Bemisia tabaci in areas of suitability for open field tomato cultivation under current and future climates. Plos One 13 (6):20. https://doi.org/10.1371/journal.pone.0198925

Schoener TW (1968) Anolis Lizards of Bimini - Resource Partitioning in a Complex Fauna. Ecology 49 (4):704-726. https://doi.org/10.2307/1935534

Shi X, Tang X, Zhang X, Zhang D, Li F, Yan F, Zhang Y, Zhou X, Liu Y (2018) Transmission Efficiency, Preference and Behavior of Bemisia tabaci MEAM1 and MED under the Influence of Tomato Chlorosis Virus. Frontiers in Plant Science 8. https://doi.org/10.3389/fpls.2017.02271

Simmons AM, Harrison HF, Ling KS (2008) Forty-nine new host plant species for Bemisia tabaci (Hemiptera: Aleyrodidae). Entomological Science 11 (4):385-390. https://doi.org/10.1111/j.1479- 
Sun DB, Liu YQ, Qin L, Xu J, Li FF, Liu SS (2013) Competitive displacement between two invasive whiteflies: insecticide application and host plant effects. Bull Entomol Res 103 (3):344-353. https://doi.org/10.1017/S0007485312000788

Tang XT, Cai L, Shen Y, Du YZ (2018) Diversity and evolution of the endosymbionts of Bemisia tabaci in China. PeerJ 6:e5516. https://doi.org/10.7717/peerj.5516

Tang XT, Cai L, Shen Y, Xu LL, Du YZ (2020) Competitive Displacement between Bemisia tabaci MEAM1 and MED and Evidence for Multiple Invasions of MED. Insects 11 (1):12.

https://doi.org/10.3390/insects11010035

Tay WT, Evans GA, Boykin LM, De Barro PJ (2012) Will the real Bemisia tabaci please stand up? PLos One 7 (11):e50550. https://doi.org/10.1371/journal.pone.0050550

Thuiller W, Albert C, Araujo MB, Berry PM, Cabeza M, Guisan A, Hickler T, Midgely GF, Paterson J, Schurr FM, Sykes MT, Zimmermann NE (2008) Predicting global change impacts on plant species' distributions: Future challenges. Perspect Plant Ecol Evol Syst 9 (3-4):137-152.

https://doi.org/10.1016/j.ppees.2007.09.004

Wang Z, Yan H, Yang Y, Wu Y (2010) Biotype and insecticide resistance status of the whitefly Bemisia tabaci from China. Pest Manag Sci 66 (12):1360-1366. https://doi.org/10.1002/ps.2023

Warren DL, Glor RE, Turelli M (2008) Environmental niche equivalency versus conservatism: quantitative approaches to niche evolution. Evolution 62 (11):2868-2883. https://doi.org/10.1111/j.1558-

5646.2008.00482.x

Warren DL, Glor RE, Turelli M (2010) ENMTools: a toolbox for comparative studies of environmental niche models. Ecography 33 (3):607-611. https://doi.org/10.1111/j.1600-0587.2009.06142.x

Xiao N, Pan LL, Zhang CR, Shan HW, Liu SS (2016) Differential tolerance capacity to unfavourable low and high temperatures between two invasive whiteflies. Scientific Reports 6:10.

https://doi.org/10.1038/srep24306

Xu J, Lin KK, Liu SS (2011) Performance on different host plants of an alien and an indigenous Bemisia tabaci from China. Journal of Applied Entomology 135 (10):771-779. https://doi.org/10.1111/j.14390418.2010.01581.x

Zang L-S, Chen W-Q, Liu S-S (2006) Comparison of performance on different host plants between the B biotype and a non-B biotype of Bemisia tabaci from Zhejiang, China. Entomol Exp Appl 121 (3):221-227. https://doi.org/10.1111/j.1570-8703.2006.00482.x 
Zhao J, Li Z, Zhang H, Chen H, Weng Q (2019) Prediction of potential distribution of tobacco whitefly Bemisia tabaci in China based on MaxEnt niche model and GIS. Journal of Plant Protection 46 (6):12921300

Zheng Y, Yao FL, Huang XY, Ding XL, He YX, Weng QY (2016) Genetic structure of the geographical populations of tobacco whitefly Bemisia tabaci (Gennadius) in Fujian, China. Acta Phytophylacica Sinica $43(1): 78-83$

\section{Tables}

Table 1. Description of the environmental variables that were considered in the MaxEnt models of $B$. tabaci species complex in this study (bold font indicates the variables in the final models) 


\begin{tabular}{lll}
\hline Variable type & Variable & Description \\
\hline Bioclimatic variables & bio1 & Annual mean temperature \\
bio2 & $\begin{array}{l}\text { Mean diurnal range (mean of monthly (max temp - } \\
\text { min temp) }\end{array}$ \\
\hline bio3 & Isothermality (bio2/bio7) (×100) \\
\hline bio4 & Temperature seasonality (standard deviation $\times 100$ ) \\
\hline bio5 & Maximum temperature of the warmest month \\
\hline bio6 & Minimum temperature of the coldest month \\
\hline bio7 & Annual temperature range (bio5 - bio6) \\
\hline bio8 & Mean temperature of the wettest quarter \\
\hline bio9 & Mean temperature of the driest quarter \\
\hline bio10 & Mean temperature of the warmest quarter \\
\hline bio11 & Mean temperature of the coldest quarter \\
\hline bio12 & Annual precipitation \\
\hline bio13 & Precipitation of the wettest month \\
\hline bio14 & Precipitation of the driest month \\
\hline bio15 & Precipitation seasonality (coefficient of variation) \\
\hline bio16 & Precipitation of the wettest quarter \\
\hline bio17 & Precipitation of the driest quarter \\
\hline bio18 & Precipitation of the warmest quarter \\
\hline bio19 & Precipitation of the coldest quarter \\
\hline Lulevation & Ground height above sea level \\
\hline & Land-use/land-cover types (see Table 2 for additional \\
\hline & details) \\
\hline & & \\
\hline & & \\
\hline & &
\end{tabular}

Table 2. The classification of land-use/land-cover variables in this study 


\begin{tabular}{|c|c|c|c|}
\hline Level $\square$ & Level $\square$ & Level $\square$ & Level $\square$ \\
\hline \multirow{3}{*}{$\begin{array}{l}1 . \\
\text { Agriculture }\end{array}$} & \multirow[t]{2}{*}{ 11. Paddy fields } & \multirow{9}{*}{\begin{tabular}{|l} 
5. Urban or built- \\
up
\end{tabular}} & 44. Permanent glacier \\
\hline & & & snow \\
\hline & 12. Dry land & & 45. Tidal flats \\
\hline 2. Forest & 21. Woodland & & 46. Beaches \\
\hline \multicolumn{3}{|r|}{ 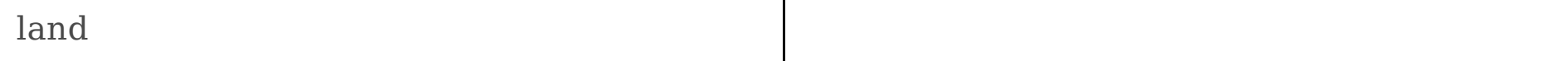 } & \\
\hline & 22. Shrubs & & 51. Urban land \\
\hline & \multirow{3}{*}{$\begin{array}{l}\text { 23. Sparse woodlands } \\
\text { 24. Other wooded land }\end{array}$} & & 52. Rural residential land \\
\hline & & & 53. Other construction \\
\hline & & & land \\
\hline \multirow[t]{4}{*}{ 3. Grassland } & \multirow{4}{*}{$\begin{array}{l}\text { 31. High-coverage grassland } \\
\text { 32. Medium-coverage } \\
\text { grassland } \\
\text { 33. Low-coverage grassland }\end{array}$} & \multirow[t]{8}{*}{ 6. Unused land } & 61. Sand \\
\hline & & & 62. Gobi \\
\hline & & & \\
\hline & & & 63. Saline/alkali land \\
\hline \multirow[t]{4}{*}{ 4. Water } & 41. River canals & & 64. Marshland \\
\hline & \multirow{3}{*}{$\begin{array}{l}\text { 42. Lakes } \\
\text { 43. Reservoir pits }\end{array}$} & & 65. Bare land \\
\hline & & & 66. Bare gravel \\
\hline & & & 67. Other unutilised land \\
\hline
\end{tabular}

Table 3. The percentage contribution and permutation importance to the four cryptic species distribution of environmental variables used in this study 


\begin{tabular}{|c|c|c|c|c|c|c|c|c|}
\hline \multirow[t]{2}{*}{ Variable } & \multicolumn{4}{|c|}{ Percentage contribution (\%) } & \multicolumn{4}{|c|}{ Permutation importance (\%) } \\
\hline & MED & MEAM1 & Asia1 & China1 & MED & MEAM1 & Asia1 & China1 \\
\hline bio1 & 13.8 & 22.1 & 66.7 & 3.1 & 24.4 & 15.9 & 96.7 & 55.5 \\
\hline bio2 & 9.8 & 1.7 & 2.1 & 2.8 & 1.6 & 12.4 & 0.6 & 6.6 \\
\hline bio3 & 2 & 3 & 27.3 & 1.8 & 0.5 & 9.5 & 2 & 0 \\
\hline bio7 & 7 & 1.1 & 0.6 & 7 & 5.5 & 1.8 & 0.5 & 9.2 \\
\hline bio12 & 1.5 & 3.5 & 0 & 18.3 & 6.5 & 5.1 & 0 & 0.1 \\
\hline bio15 & 7.5 & 0.9 & 0.3 & 1.6 & 2.9 & 2.2 & 0 & 0.6 \\
\hline bio19 & 1.6 & 0.4 & 0 & 34.4 & 4.8 & 0.1 & 0 & 0.4 \\
\hline elev & 14.3 & 17.3 & 0.2 & 20.8 & 36.3 & 29.8 & 0 & 26.2 \\
\hline LULC & 42.6 & 50 & 2.7 & 10.3 & 17.4 & 23.2 & 0.2 & 1.4 \\
\hline
\end{tabular}

Table 4. Areas of suitable habitat of the four cryptic species of B. tabaci in China.

\begin{tabular}{llllll}
\hline Areas of suitability levels (10,000 & Low & Moderate & High & Total & Total area in \\
$\left.\mathrm{km}^{2}\right)$ & suitability & suitability & suitability & & China (\%) \\
\hline MED & 109.2367 & 48.6821 & 36.1501 & 194.0689 & 20.23 \\
MEAM1 & 141.2710 & 24.3394 & 15.3651 & 180.9754 & 18.86 \\
\hline Asia1 & 47.9735 & 14.1612 & 19.0654 & 81.2001 & 8.46 \\
\hline China1 & 44.8141 & 37.5872 & 34.3801 & 116.7815 & 12.17 \\
\hline
\end{tabular}

Table 5. The ecological niche breadth, niche overlap, and range overlap between different cryptic species of B. tabaci

\begin{tabular}{|c|c|c|c|c|c|c|c|c|c|c|}
\hline \multirow{3}{*}{$\begin{array}{l}\text { Cryptic } \\
\text { species }\end{array}$} & \multirow{3}{*}{$\begin{array}{l}\text { Niche } \\
\text { breadth }\end{array}$} & \multicolumn{6}{|c|}{ Niche overlap } & \multirow{2}{*}{\multicolumn{3}{|c|}{ Range overlap }} \\
\hline & & \multicolumn{3}{|l|}{$D$} & \multicolumn{3}{|l|}{$I$} & & & \\
\hline & & MEAM1 & Asia1 & China1 & MEAM1 & Asia1 & China1 & MEAM1 & Asia1 & China1 \\
\hline MED & 0.2694 & 0.7114 & 0.3738 & 0.4662 & 0.9291 & 0.7247 & 0.7610 & 0.7272 & 0.4260 & 0.3202 \\
\hline MEAM1 & 0.2400 & & 0.4767 & 0.5442 & & 0.7877 & 0.8117 & & 0.4242 & 0.4182 \\
\hline Asia1 & 0.0830 & & & 0.3711 & & & 0.6784 & & & 0.0278 \\
\hline China1 & 0.1603 & & & & & & & & & \\
\hline
\end{tabular}



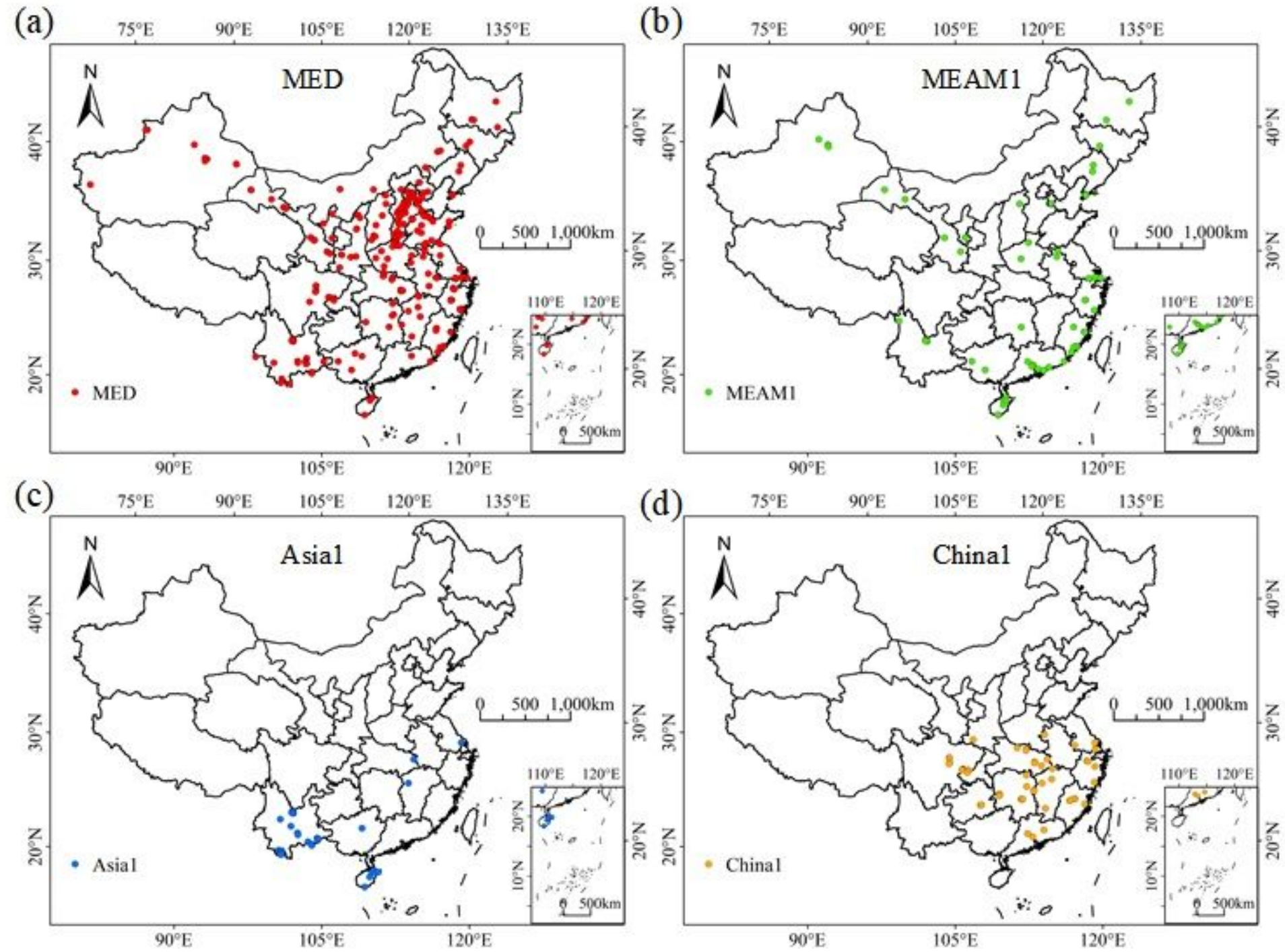

Figure 1

The occurrence records of the Bemisia. tabaci species complex, including four cryptic species: (a) MED, (b) MEAM1, (c) Asia1, and (d) China1, which were used as the presence data in MaxEnt modelling. Note: The designations employed and the presentation of the material on this map do not imply the expression of any opinion whatsoever on the part of Research Square concerning the legal status of any country, territory, city or area or of its authorities, or concerning the delimitation of its frontiers or boundaries. This map has been provided by the authors. 
(a)

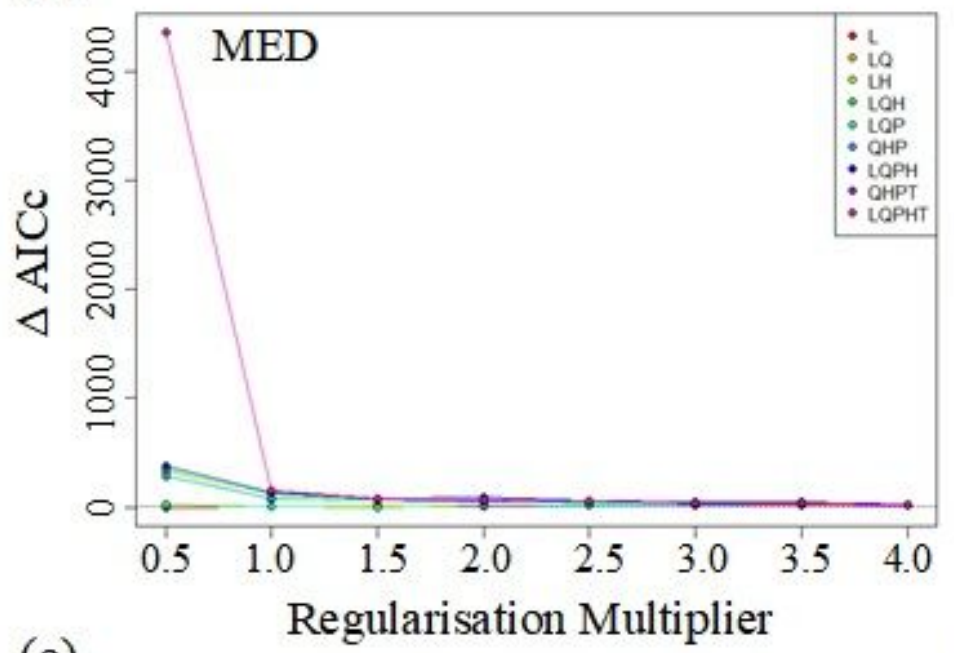

(c)

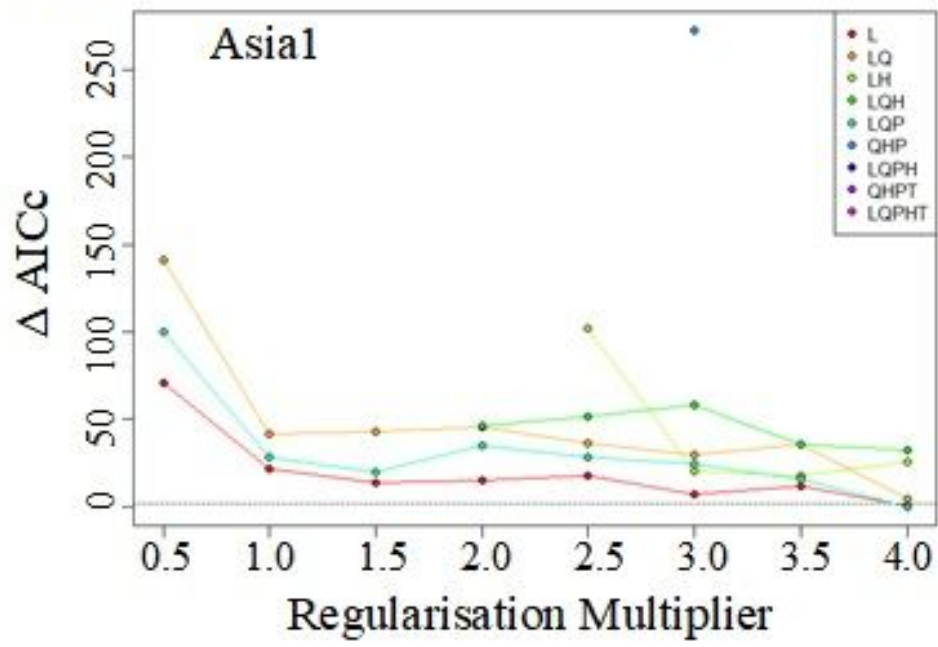

(b)

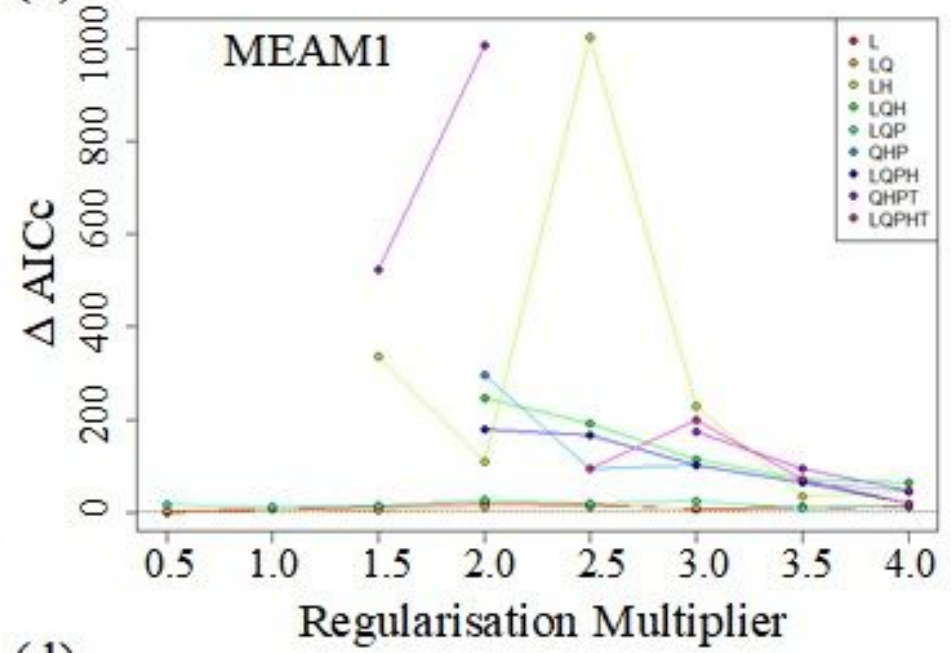

(d)

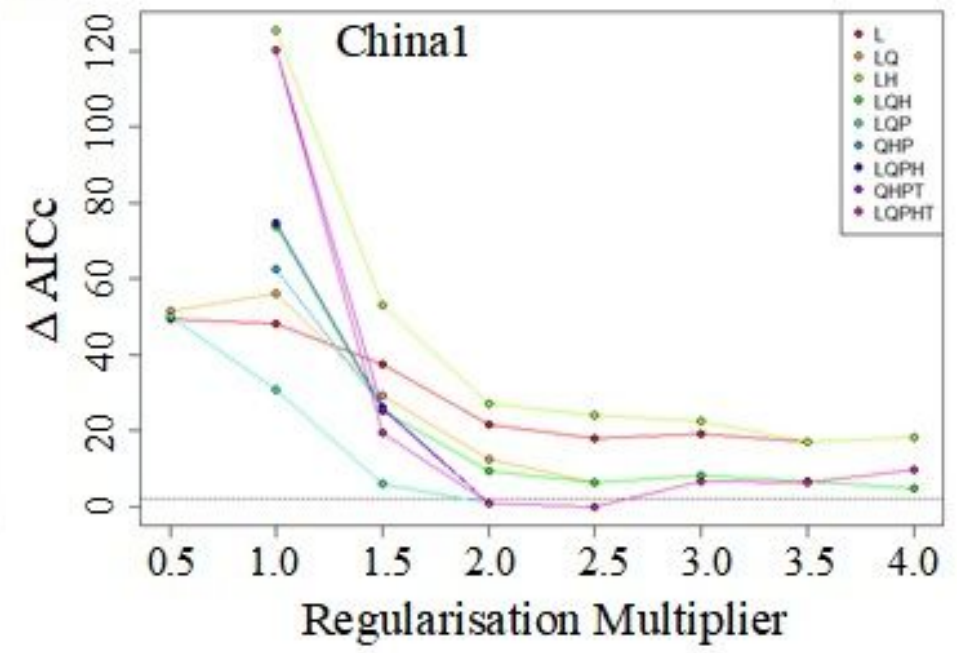

Figure 2

The results of ENMeval package for the four cryptic species of Bemisia. tabaci, which showed that the best combinations of FCs and RM in the MaxEnt models were: (a) LQP and 1.5 for MED, (b) L and 0.5 for MEAM1, (c) LQP and 4.0 for Asia1, and (d) LQHP and 2.0 for China1, respectively 
(a)

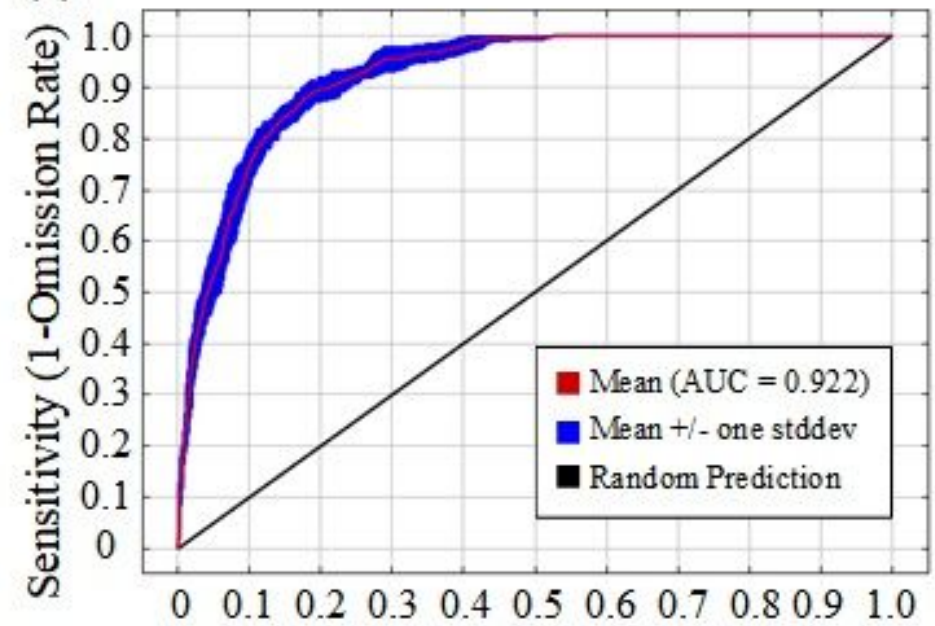

1-Specificity (Fractional Predicted Area)

(c)

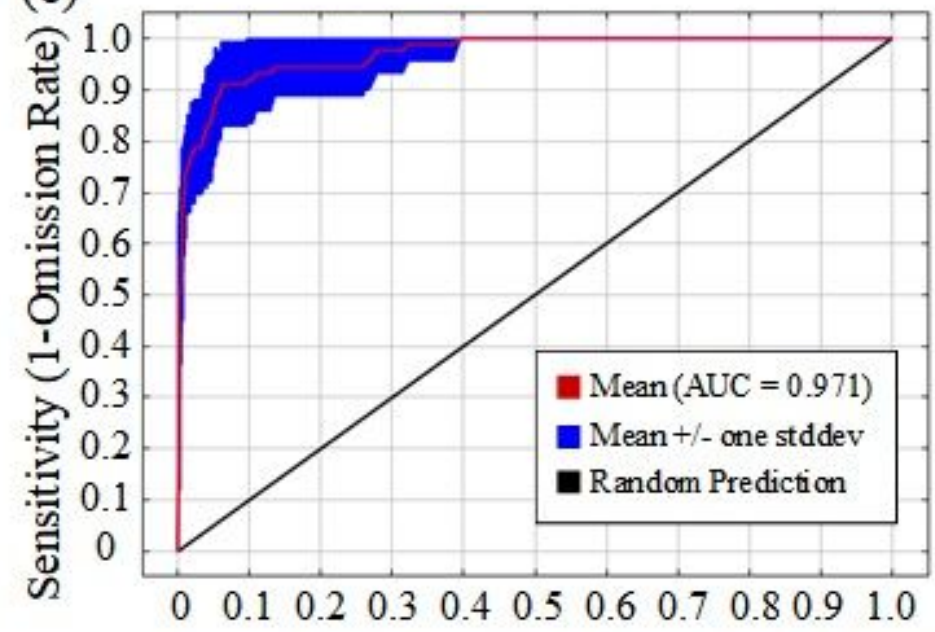

1-Specificity (Fractional Predicted Area) (b)

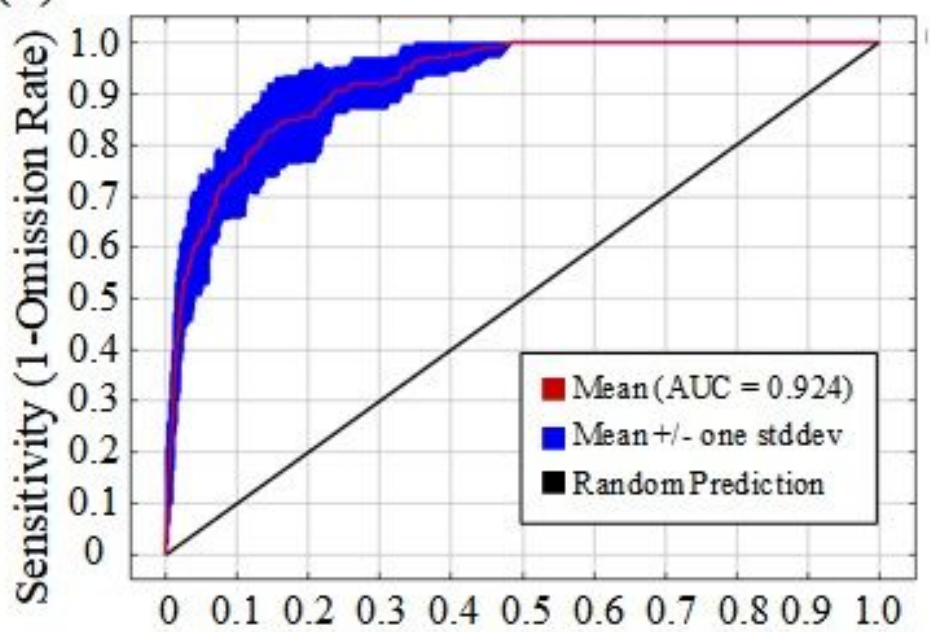

(d)

1-Specificity (Fractional Predicted Area)



1-Specificity (Fractional Predicted Area)

Figure 3

Receiver operating characteristic (ROC) curve verification of the prediction for the four cryptic species of Bemisia tabaci in China by MaxEnt, (a) MED, (b) MEAM1, (c) Asia1, and (d) China1 
(a)

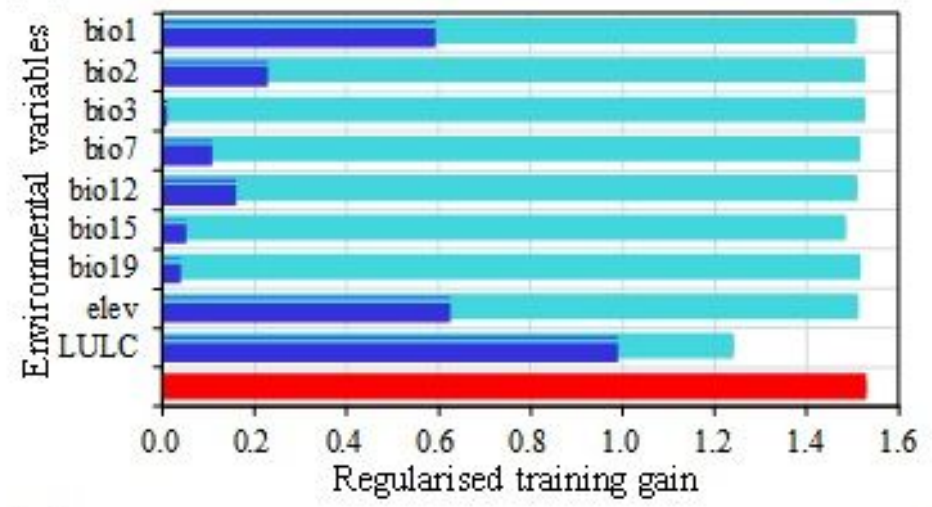

(c)



(b)

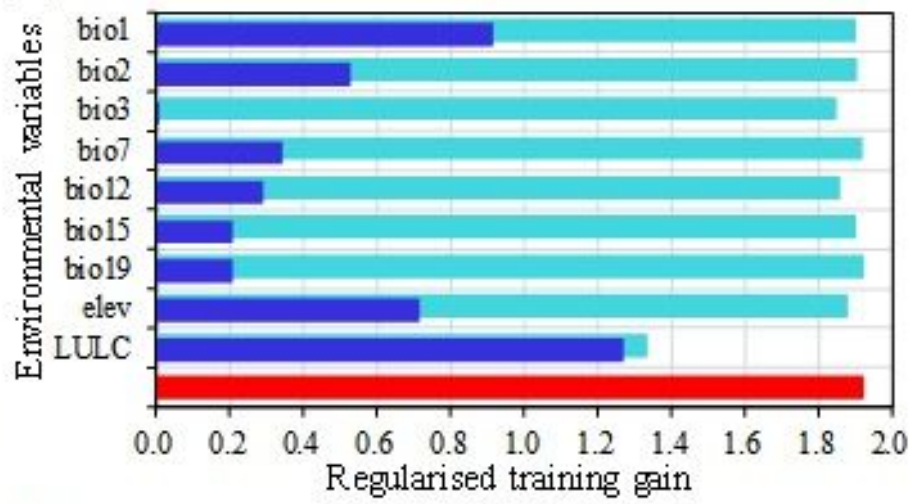

(d)

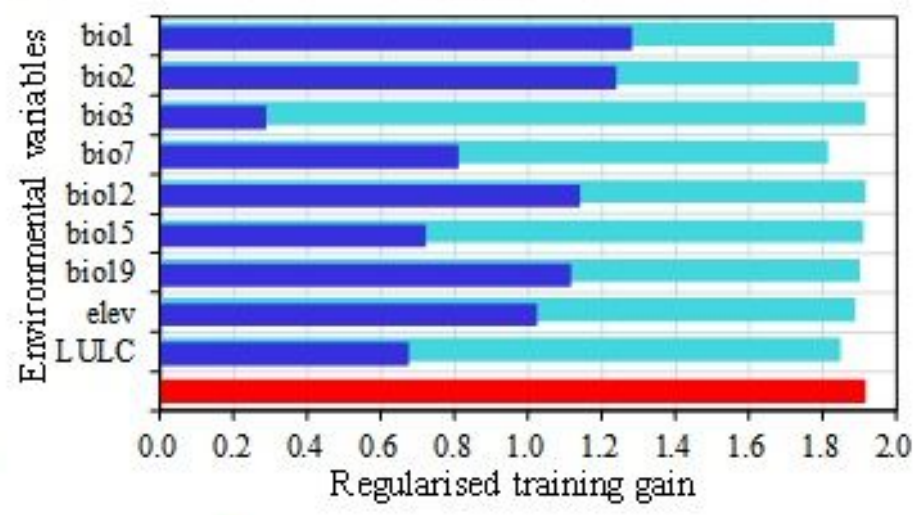

without variable

with only variable

with all variable

Figure 4

Jackknife results of habitat distribution prediction for Bemisia. tabaci cryptic species. (a) MED, (b) MEAM1, (c) Asia1, and (d) China1 

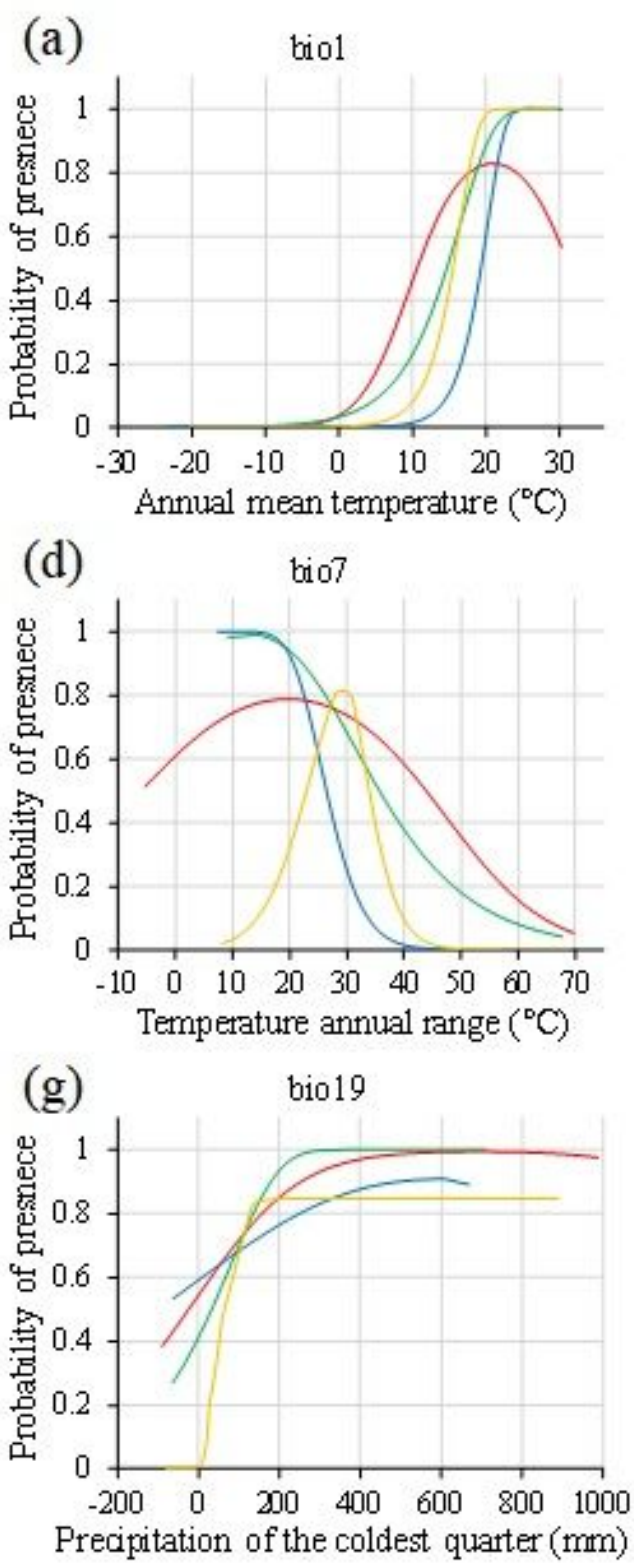

(b) bio2

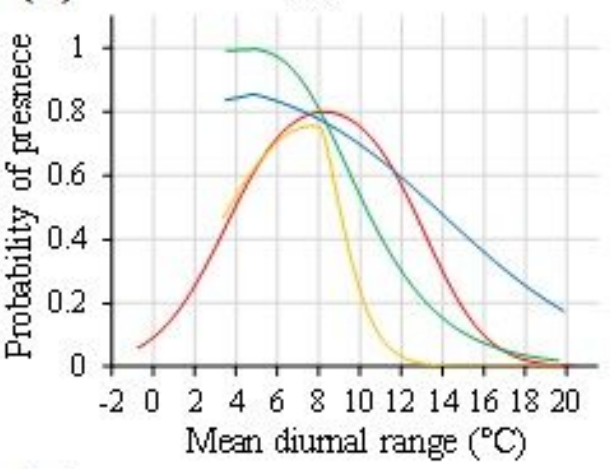

(e)

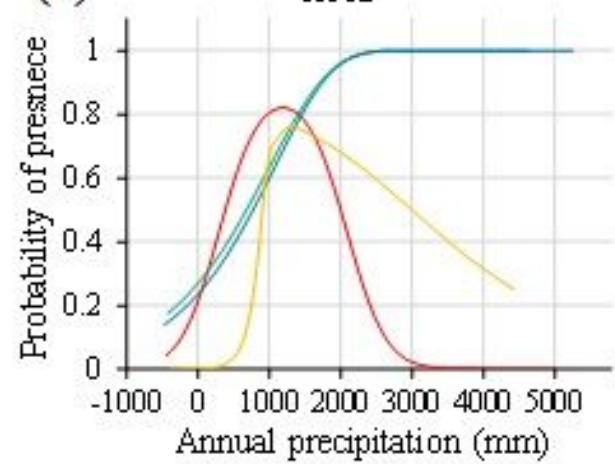

(h)

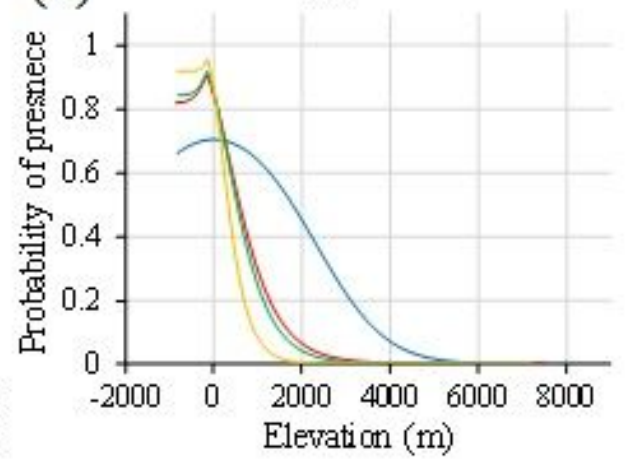

(c) bio3

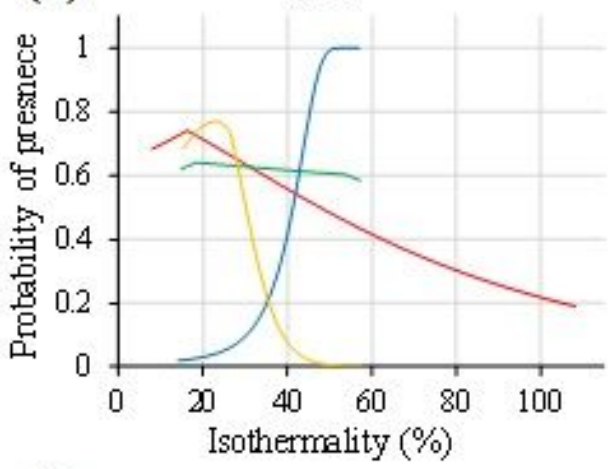

(f)

bio 15

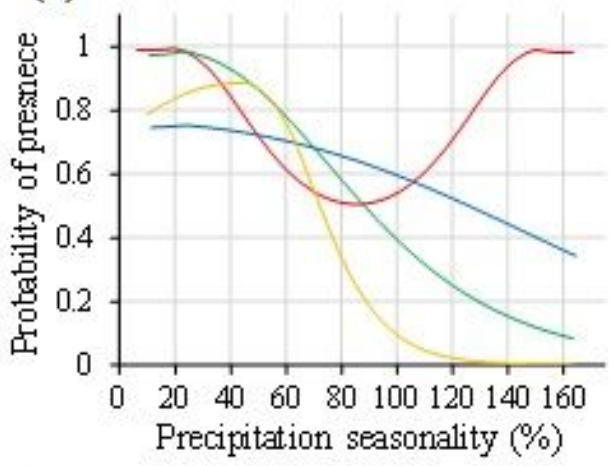

(i)

LULC

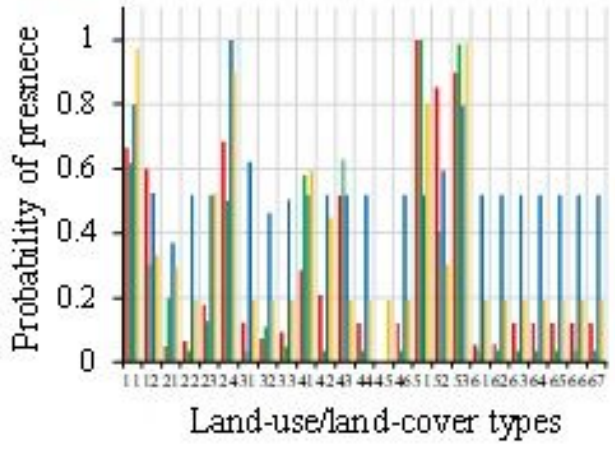

-MED - MEAM1 - Asial - China1

\section{Figure 5}

Response curve showing the relationships between the probability of presence of the four cryptic species of Bemisia. tabaci and nine environmental variables. Values shown are the average over 10 replicate runs by MaxEnt 

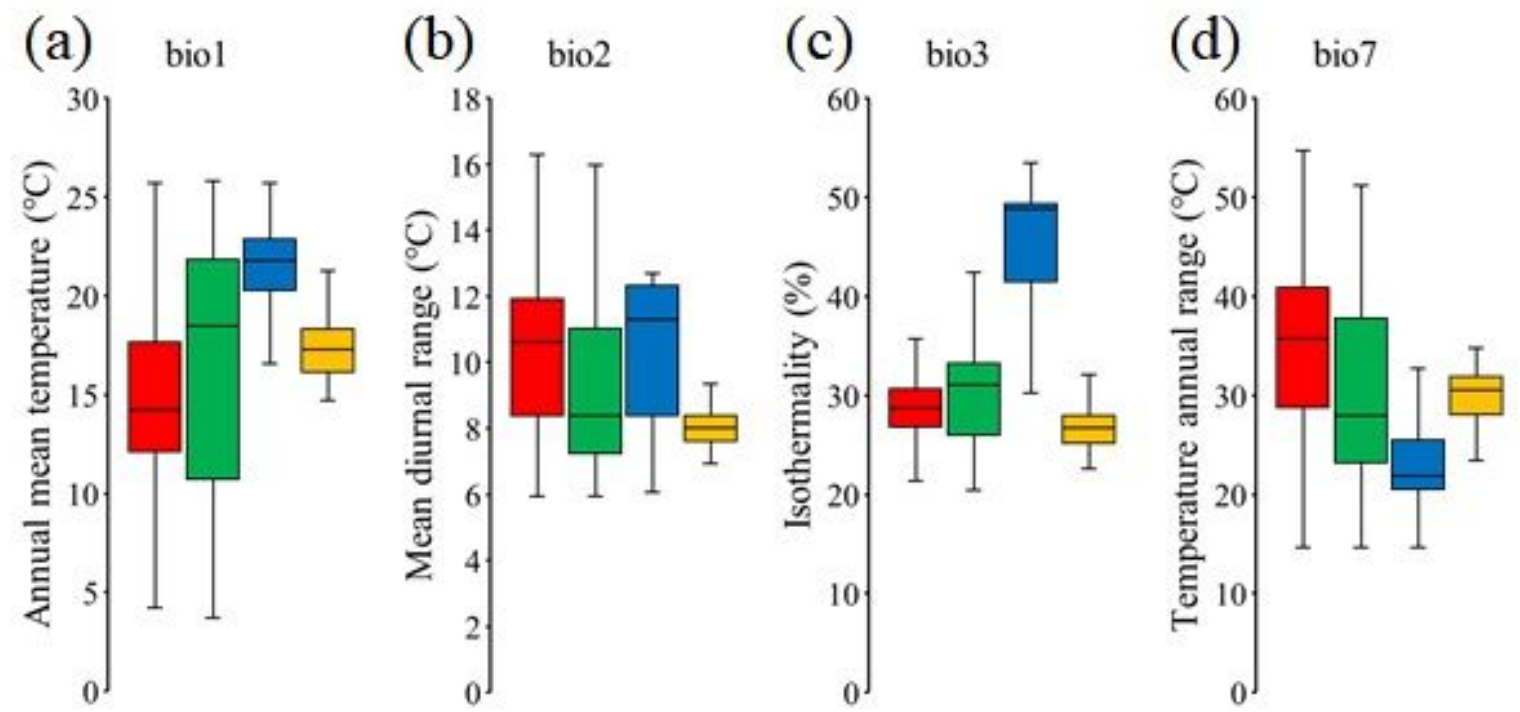

(i) LULC
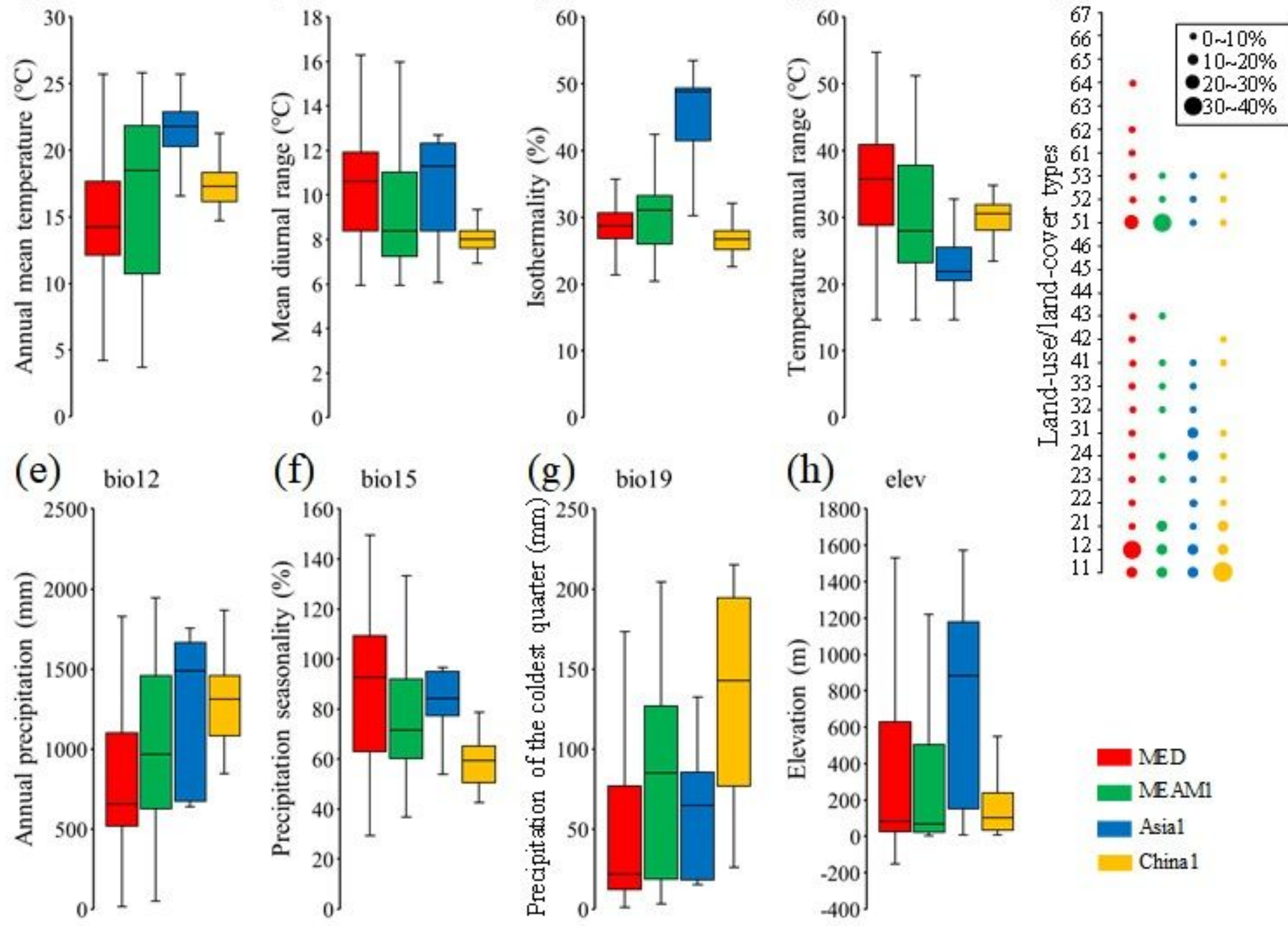

Figure 6

The adaptation range of different environmental variables for the four cryptic species of Bemisia. tabaci in China, (a) annual mean temperature (bio1), (b) mean diurnal range (bio2), (c) isothermality (bio3), (d) annual temperature range (bio7), (e) annual precipitation (bio12), (f) precipitation seasonality (bio15), (g) precipitation of coldest quarter (bio19), (h) elevation (elev), and (i) land-use/land-cover types (LULC) 
(a)

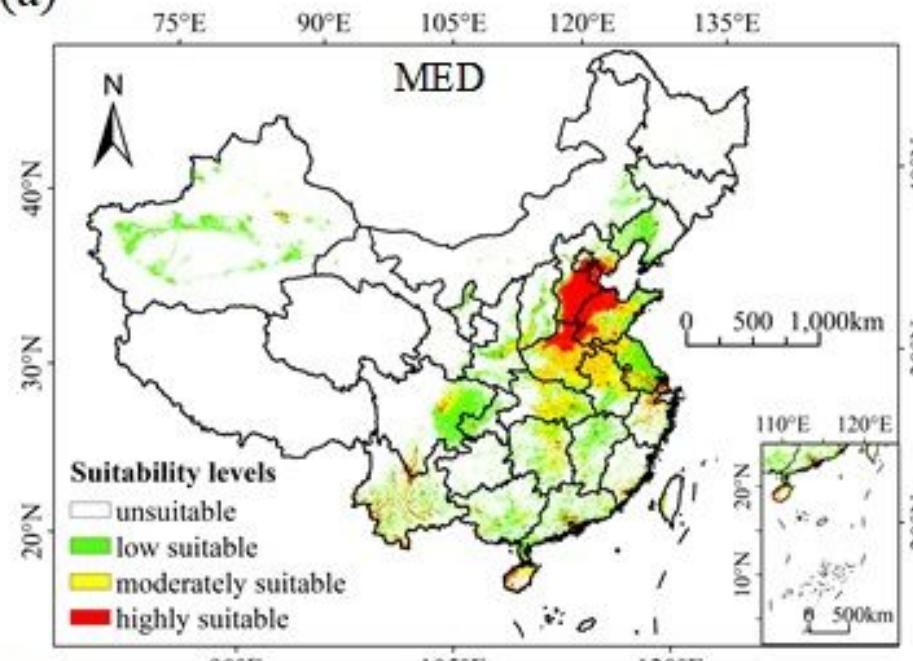

(c)

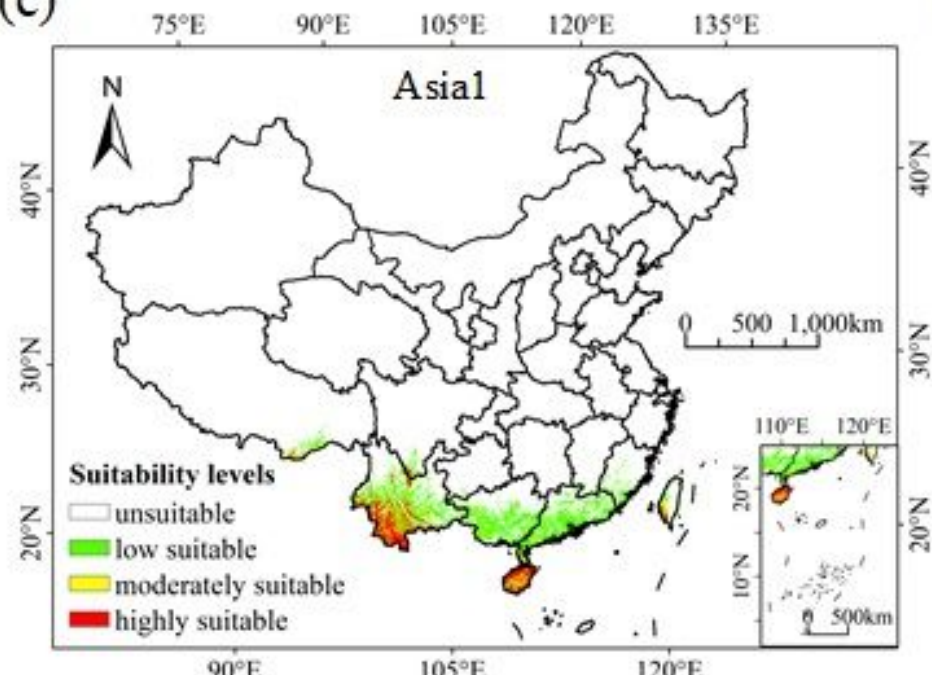

(b)

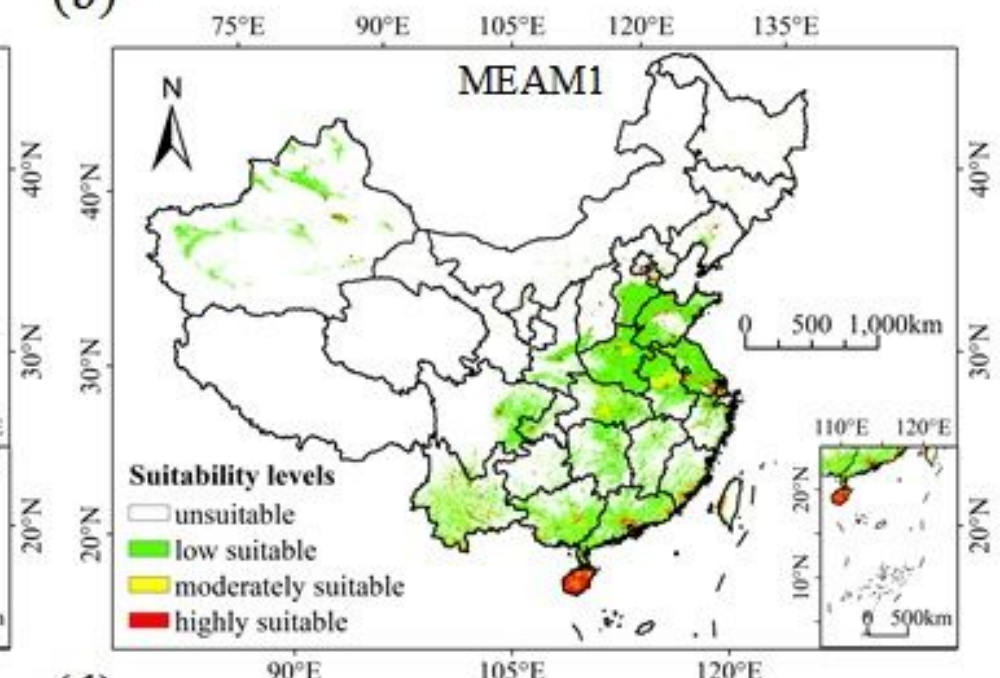

(d)

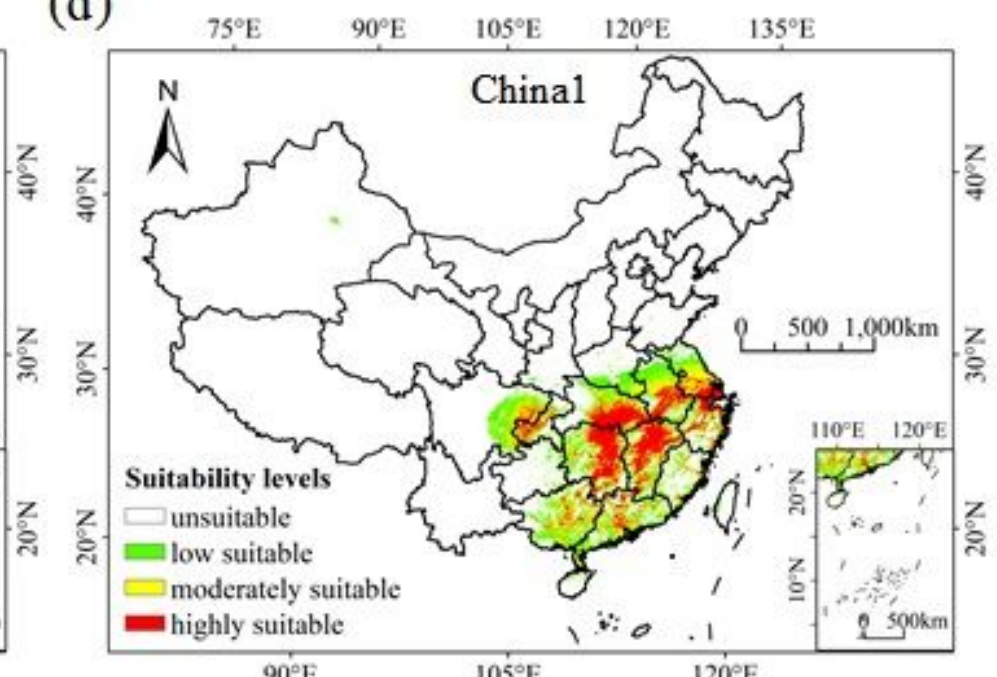

Figure 7

The suitable habitat distribution of the four cryptic species of Bemisia. tabaci in China. (a) MED, (b) MEAM1, (c) Asia1, and (d) China1 Note: The designations employed and the presentation of the material on this map do not imply the expression of any opinion whatsoever on the part of Research Square concerning the legal status of any country, territory, city or area or of its authorities, or concerning the delimitation of its frontiers or boundaries. This map has been provided by the authors.

\section{Supplementary Files}

This is a list of supplementary files associated with this preprint. Click to download.

- Supplementarymaterial.xlsx 